\title{
STUDI BIOMASSA LAMUN (Enhalus acoroides L.) DAN (Halodule pinifolia) BERDASARKAN KEDALAMAN AIR LAUT DI PANTAI DESA TANJUNG TIRAM SULAWESI TENGGARA
}

\section{BIOMASS STUDY OF (Enhalus acoroides L.) AND (Halodule pinifolia) BASED ON THE DEPTH OF SEA WATER IN TANJUNG TIRAM VILLAGE BEACH SOUTHEAST SULAWESI}

\author{
Lisdawati $^{(1)}$, Sitti Wirdhana Ahmad ${ }^{(2)}$, La Ode Siwi ${ }^{(3)}$ \\ (1) Mahasiswa Program Studi Biologi FMIPA Universitas Halu Oleo Kendari \\ ${ }^{(2,3)}$ Dosen Program Studi Biologi FMIPA Universitas Halu Oleo Kendari \\ ${ }^{(1)}$ Corresponding Email Author : lisdawatisayhrir@gmail.com
}

\begin{abstract}
ABSTRAK
Penelitian ini bertujuan untuk mengetahui biomassa dan faktor lingkungan yang mempengaruhi kandungan biomassa lamun Enhalus acorroides L. dan Halodule pinifolia berdasarkan kedalaman air laut di Pantai Desa Tanjung Tiram. Penelitian ini telah dilakukan pada bulan Juni - Agustus 2018. Penelitian ini bersifat eksploratif. Pengambilan sampel dilakukan pada tiga titik pengamatan dengan menggunakan metode purposif sampling berdasarkan kedalaman perairan yaitu kedalaman 1 meter, 2 meter dan 3 meter. Hasil penelitian menunjukkan bahwa kandungan biomassa lamu Enhalus acorroides $L$. yang terdapat pada kedalaman $1 \mathrm{~m}$ total biomassa $316,73 \mathrm{~g} / \mathrm{m}^{2}$, kedalaman $2 \mathrm{~m}$ total biomassa $197,56 \mathrm{~g} / \mathrm{m}^{2}$ dan kedalaman $3 \mathrm{~m}$ total biomassa $38,26 \mathrm{~g} / \mathrm{m}^{2}$. Kandungan biomassa jenis lamun Halodule pinifolia pada kedalaman $1 \mathrm{~m}$ total biomassa $1,6 \mathrm{~g} / \mathrm{m}^{2}$, kedalaman $2 \mathrm{~m}$ total biomassa $2,97 \mathrm{~g} / \mathrm{m}^{2}$ dan kedalaman $3 \mathrm{~m}$ total biomassa $0,25 \mathrm{~g} / \mathrm{m}^{2}$. Faktor lingkungan yang mempengaruhi kandungan biomassa lamun Enhalus acorroides L. dan Halodule pinifolia pada Perairan Pantai Desa Tanjung Tiram yaitu substrat, kandungan bahan organik (KOT), intensitas cahaya, suhu, salinitas dan kekeruhan.
\end{abstract}

Kata kunci : Biomassa, Enhalus acorroides L. dan Halodule pinifolia

\section{ABSTRACT}

This study aims to determine the biomass and environmental factors that influence the seagrass biomass content of Enhalus acorroides L. and Halodule pinifolia based on the depth of sea water in Tanjung Tiram Village Beach. This research was conducted during June-August 2018. This research was explorative. Sampling area were carried out at three points by observation using purposive sampling method depth water depth of 1 meter, 2 meter and 3 meter. The biomass was estimated in the plot, while enviromental factors that influence the seagrass biomass content of Enhalus acorroides L. and Halodule pinifolia in Tanjung Tiram Village Beach are substrate, nutrient content (KOT), light intensity, temperature, salinity and turbidity. The results showed that Enhalus acorroides $L$ biomass contained at a depth of $1 \mathrm{~m}$ total biomass of $316.73 \mathrm{~g} / \mathrm{m}^{2}$, depth of 2 $\mathrm{m}$ total biomass of $197.56 \mathrm{~g} / \mathrm{m}^{2}$ and depth of $3 \mathrm{~m}$ total biomass of $38.26 \mathrm{~g} / \mathrm{m}^{2}$. Biomass content of Halodule pinifolia seagrass at a depth of $1 \mathrm{~m}$ total biomass of $1.6 \mathrm{~g} / \mathrm{m}^{2}$, depth of $2 \mathrm{~m}$ total biomass of $2.97 \mathrm{~g} / \mathrm{m}^{2}$ and a depth of $3 \mathrm{~m}$ of total biomass of $0.25 \mathrm{~g} / \mathrm{m}^{2}$.

Keywords: Biomass, Enhalus acorroides L. and Halodule pinifolia 


\section{PENDAHULUAN}

Ekosistem lamun merupakan salah satu ekosistem perairan laut dangkal yang membentuk suatu hamparan padang lamun (Hermawan, dkk., 2017). Ekosistem lamun memiliki tingkat produktifitas tertinggi sehingga menjadikan lamun (seagrass) sebagai produktifitas primer pada wilayah perairan dangkal dan merupakan sumber makanan yang sangat penting bagi banyak organisme, terutama bagi biota yang memanfaatkan padang lamun (seagrass) sebagai habitatnya (Wakano, 2013).

Provinsi Sulawesi Tenggara adalah salah satu provinsi yang terletak di kawasan Indonesia bagian Tengah yang memiliki panjang pantai kurang lebih $1.740 \mathrm{~km}$ serta memiliki potensi sumber daya lamun yang cukup besar (Suherlan, dkk., 2015). Perairan Pantai Desa Tanjung Tiram Konawe Selatan merupakan salah satu kawasan perairan yang terletak di Provinsi Sulawesi Tenggara dan memiliki padang lamun yang cukup luas dan masih terjaga.

Pantai Desa Tanjung Tiram terletak pada titik koordinat $4^{\circ} 2^{\prime} 15,5^{\prime \prime}$ LS dan 122 40 '17,6"BT. Menurut Rahman, dkk (2016) kondisi Pantai Tanjung Tiram, Konawe Selatan yang landai dengan substrat yang berlumpur mempengaruhi kerapatan dan pola pertumbuhan jenis lamun (seagrass). Penelitian yang dilakukan oleh Supriatna (2017) di perairan Pantai Desa Tanjung Tiram terdapat 2 famili lamun yang ditemukan yaitu Hydrocaritaceae dan Cymodoceaceae dengan jumlah spesies sebanyak 10 spesies. Persentase kehadiran lamun yang paling banyak ditemukan di perairan Pantai Desa Tanjung Tiram yaitu jenis Enhalus acoroides L. dan jenis Halodule pinifolia.

Secara morfologi Enhalus acoroides L. merupakan jenis lamun yang memiliki struktur morfologi paling besar. Enhalus acoroides L. hidup di zona intertidal sampai kedalaman $6 \mathrm{~m}$. Enhalus acoroides L. seringkali mendiami daerah - daerah yang masih terendam air pada saat surut di daerah litoral dan spesies ini tidak akan ditemui jika banyak sungai bermuara di pesisir tersebut (Hartog, 1977).

Halodule pinifolia tergolong jenis lamun yangpertumbuhannya cepat dan merupakan jenis pionir Halodule pinifolia umumnya dijumpai pada daerah intertidal dan biasanya tumbuh pada substrat berpasir atau berlumpur. Jenis lamun ini mampu tumbuh sampai kedalaman $25 \mathrm{~m}$ (Hutomo, 1997). Lamun jenis Halodule pinifolia memiliki pembuluh berupa garis lurus pada 
bagian tengah daun sebagai ciri khas genus Halodule.

Pertumbuhan lamun dipengaruhi oleh beberapa faktor yaitu kedalaman air, suhu, intensitas cahaya, salinitas, substrat dan kandungan organik total (KOT). Salah satu faktor yang sangat berpengaruh terhadap pertumbuhan dan penyebaran lamun (seagrass) yaitu kedalaman air. Kedalaman air akan mempengaruhi cahaya yang masuk kedalam perairan. Hal ini akan mempengaruhi pertumbuhan lamun, ketika intensitas cahaya yang masuk kedalam perairan berkurang maka lamun (seagrass) akan sulit berfotosintesis dan proses tersebut akan mempengaruhi produktifitas biomassa lamun (seagrass).

Penelitian mengenai lamun (seagrass) di Indonesia sudah banyak dilakukan baik mengenai pola sebaran, keanekaragaman maupun aspek ekologinya (Ridio, 2004), namun penelitian tentang biomassa lamun terhadap tingkat kedalaman air laut, khususnya di perairan Pantai Desa Tanjung Tiram belum pernah dilakukan. Hal tersebut menarik perhatian peneliti untuk melakukan penelitian mengenai Studi Biomassa Lamun Enhalus acoroides L. dan Halodule pinifolia. Berdasarkan Tingkat
Kedalaman Air Laut di Pantai Desa Tanjung Tiram Sulawesi Tenggara.

\section{METODE PENELITIAN}

\section{Alat dan Bahan}

Alat yang digunakan dalam peneltian ini meliputi GPS, pipa, kamera digital,oven, timbangan analitik, alat tulis, Lux meter, meter, Thermometer, Handrefracto meter, turbidimeter dan tanur. Bahan yang digunakan dalam penelitian ini adalah Sampel substrat, lamun Enhalus acoroides L. dan Halodule pinifolia.

\section{Penetapan Lokasi}

Penelitian ini berlokasi di Pantai Desa Tanjung Tiram, Sulawesi Tenggara. Pengambilan sampel dilakukan secara purposive sampling pada 3 titik lokasi pengamatan. Pada titik I (krdalaman $1 \mathrm{~m})$ dengan koordinat $04^{\circ} 02{ }^{\prime} 21,1^{\prime \prime}$ Lintang Selatan dan $122^{\circ} 40^{\prime} 23,6^{\prime \prime}$ Bujur Timur, titik II (kedalaman $2 \mathrm{~m}$ ) dengan koordinat $04^{\circ} 02^{\prime} 23,5^{\prime \prime}$ Lintang Selatan dan 122 40'21,2" Bujur Timur dan titik III (kedalaman 3 m) 04 02'23,2" Lintang Selatan dan 122 $42^{\circ} 21,2^{\prime \prime}$ Bujur timur.

\section{Pemasangan Plot Pengamatan}

Pemasangan plot pengamatan dilakukan pada titik pengamatan yang telah ditentukan.Plot yang dipasang sebanyak 3 plot pengamatan pada masing-masing 
titik pengamatan. Plot yang digunakan berukuran $1 \mathrm{~m} \times 1 \mathrm{~m}$ dan bagian dalam plot dibuat sub plot sebanyak 25 sub plot. Pemasangan plot pengamatan dilakukan secara purposif sampling.

Kedalaman Air Laut

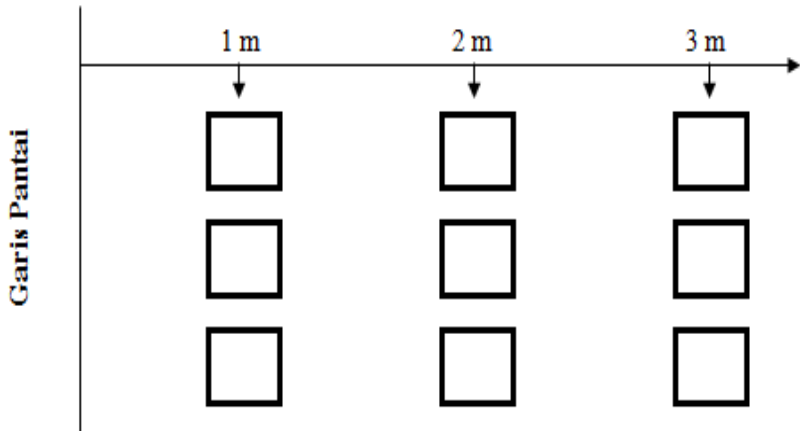

Gambar 1. Sketsa Pemasangan Plot

\section{Pengukuran Parameter Perairan}

\section{a. Suhu}

Pengukurun suhu perairan dilakukan dengan cara memasukkan ujung Thermom ke dalam permukaan air sampai menunjukkan skala yang tetap. Pengukuran suhu dilakukan pada pagi hari pukul 09.00 WITA, dikarenakan pada kisaran waktu tersebut belum terjadi peningkatan suhu diperaian karena pada siang hari perairan lebih banyak menerima pemanasan dari sinar matahari (Merryanto, 2000).

\section{b. Intensitas Cahaya}

Pengukuran intensitas cahaya dilakukan dengan menggunakan luxmeter. Prosedur penggunaannya yaitu dengan cara megarahkan sensor lux meter ke arah cahaya matahari kemudian melihat angka yang tertera pada layar lux meter.

\section{c. Kedalaman air}

Pengukuran kedalaman air dilakukan untuk mengetahui kedalaman air pada titik pengamatan. Pengukuran untuk kedalaman perairan dilakukan dengan cara menggunakan tali rafia yang sudah diukur terlebih dahulu sesuai dengan tingkat kedalaman perairan yang akan diteliti, kemudian diberi pemberat untuk memudahkan pada saat pengukuran kedalaman perairan.

\section{d. Salinitas}

Pengukuran untuk salinitas menggunakan alat Handrefractometer dengan memasukkan 1 tetes sampel air laut dan diukur kadar salinitas yang tertera pada skalanya.

\section{e. Substrat}

Sampel substrat diambil pada lokasi atau titik yang sudah ditentukan. Pada pengambilan sampel substrat menggunakan pipa paralon yang berdiam $5 \mathrm{~cm}$. Pipa paralon dibenamkan dalam substrat dengan kedalaman $10 \mathrm{~cm}$ lalu diangkat, kira-kira 100 gram sampel substrat. 


\section{f. Kekeruhan Air}

Kekeruhan air merupakan parametereter perairan yang sangat penting, karena secara langsung kekeruhan mempengaruhi penetrasi cahaya yang masuk kedalam perairan sehingga mempengaruhi proses fotosintesis pada lamun. Kekeruhan air dapat diukur menggunakan turbidi meter.

\section{g. Kandungan Bahan Organik Total (KOT)}

Bahan organik merupakan unsur hara yang sangat dibutuhkan oleh ekosistem didalam perairan (Hutasoit, dkk., 2014). Adapun analisis kandungan organik total dilakukan dengan menggunakan rumus persamaan Allen et al., (1976) sebagai berikut :

$$
\mathrm{Li}=\frac{\mathrm{Wo}-\mathrm{Wt}}{\mathrm{Wo}} \times 100 \%
$$

Keterangan :

$\begin{array}{ll}\mathrm{Li} & \text { : Losonignation (\%) } \\ \mathrm{Wo} & \text { : Berat awal (gram) } \\ \mathrm{Wt} & \text { : Berat akhir (gram) }\end{array}$

\section{Pengambilan Sampel pada Plot Pengamatan}

Pengambilan sampel pada plot pengamatan dilakukan dengan cara mengambil sampel lamun Enhalus acoroides L. dan Halodulepinifolia yang terdapat pada masing-masing plot pengamatan pada kedalaman perairan yaitu $1 \mathrm{~m}, 2 \mathrm{~m}$ dan $3 \mathrm{~m}$, kemudian dimasukkan kedalam plastik sampel.Selain itu, dilakukan penghitungan jumlah tegakan spesies Enhalus acoroides L. dan Halodulepinifolia pada sub plot yang telah ditentukan.

\section{Menimbang Berat Basah Sampel}

Sampel lamun Enhalus acoroides L. dan Halodulepinifolia yang telah diambil kemudian dibersihkan terlebih dahulu (dicuci dengan air) dan memisahkan masing-masing bagian organ lamun (seagrass) seperti akar, rhizoma dan daun, kemudian dikering anginkan terlebih dahulu danmenimbang berat basah sampel lamun Enhalus acoroides L. dan Halodulepinifolia.

\section{Mengoven Sampel}

Pengovenan sampel lamun Enhalus acoroides L. dan Halodulepinifolia dimasukkan kedalam oven dengan suhu $65^{\circ} \mathrm{C}$ selama 48 jam, agar sampel lamun Enhalus acoroides L. dan Halodulepinifolia benar-benar kering (Hendra, 2011).

\section{Menimbang Berat Kering Sampel}

Penimbangan berat kering sampel dilakukan setelah sampel lamun Enhalus acoroides L. dan Halodulepinifolia dioven, kemudian masing-masing bagian organ lamun (akar, rhizoma dan daun) ditimbang 
berat keringnya menggunakan timbangan analitik.

\section{Biomassa Sampel}

Biomassa lamun Enhalus acoroides L. dan Halodulepinifolia dari hasil penimbangan berat kering sampel dengan menggunakan timbangan analitik hingga didapat berat konstan.

\section{Kerapatan Jenis Lamun}

Kerapatan jenis lamun dapat dihitung menggunakan rumus sebagai berikut :

$$
\mathrm{K}=\frac{n i}{\mathrm{~A}}
$$

Keterangan :

$\mathrm{K}$ : kerapatan lamun ke- $i$ (tegakan $\left./ \mathrm{m}^{2}\right)$

$n i$ : jumlah total individu dari jenis ke- $i$ (tegakan)

A : luas area total pengambilan sampel

\section{HASIL DAN DISKUSI}

\section{A. Gambaran lokasi penelitian}

Titik I lokasi penelitian terletak pada titik koordinat $04^{\circ} 02$ ' $21,1^{\prime \prime}$ LS dan $122^{\circ} 40^{\prime} 23,6^{\prime \prime} B T$ dengan kedalaman $1 \mathrm{~m}$ yang letaknya sangat dekat dengan ekosistem mangrove dengan tipe substrat lumpur berpasir. Titik penelitian ini dekat dengan pemukiman warga perairan pantai desa tanjung tiram dan sangat dekat dengan tempat penambatan perahu para nelayan. Titik II pada titik koordinat $04^{\circ} 02$ '23,5" LS dan $122^{\circ} 40^{\prime} 21,2^{\prime \prime B T}$ dengan kedalaman $2 \mathrm{~m}$ memiliki kondisi substrat yang cenderung berpasir. Titik III pada titik koordinat $04^{\circ} 02^{\prime} 23,2^{\prime \prime}$ LS dan $122^{\circ} 40^{\prime} 21,2^{\prime \prime B T}$ dengan kedalaman $3 \mathrm{~m}$ memiliki substrat yang cenderung berpasir dengan pecahan karang.

\section{B. Pengukuran Parameter Perairan}

Hasil pengukuran parameter lingkungan pada penelitian ini disajikan pada Tabel 1.

Tabel 1. Data pengukuran parameter perairan

\begin{tabular}{clccc}
\hline \multirow{2}{*}{ No. } & Parameter & \multicolumn{3}{c}{ Titik } \\
\cline { 3 - 5 } & & I & II & III \\
\hline 1. & Suhu $\left({ }^{\circ} \mathrm{C}\right)$ & 29 & 30 & 30 \\
\hline 2. & $\begin{array}{l}\text { Intensitas } \\
\text { cahaya } \\
\text { (Cd) }\end{array}$ & 817 & 801 & 778 \\
\hline 3. & $\begin{array}{l}\text { Kedalaman } \\
\text { air (m) }\end{array}$ & 1 & 2 & 3 \\
\hline 4. & $\begin{array}{l}\text { Salinitas } \\
\text { (\%o) }\end{array}$ & 31 & 30 & 30 \\
\hline 5. & $\begin{array}{l}\text { Kekeruhan } \\
\text { (NTU) }\end{array}$ & 1,0 & 0,7 & 0,5 \\
\hline 6. & Substrat & $\begin{array}{c}\text { Pasir } \\
\text { berlum } \\
\text { pur }\end{array}$ & Pasir & $\begin{array}{c}\text { Pasir } \\
\text { pecahan } \\
\text { karang }\end{array}$ \\
\hline 7. & KOT (\%) & $\begin{array}{c}0,65 \\
0,51\end{array}$ & 0,27 \\
\hline
\end{tabular}

Hasil pengukuran suhu pada penelitian ini yaitu pada kisaran 29-30 ${ }^{\circ} \mathrm{C}$. lamun mampu mentolerir suhu perairan pada kisaran $20^{\circ} \mathrm{C}-36^{\circ} \mathrm{C}$ dan suhu optimal untuk melakukan fotosintesis pada kisaran $28^{\circ} \mathrm{C}-30^{\circ} \mathrm{C}$ (Dahuri, 2003).Dari hasil pengukuran suhu yang dilakukan di Perairan Pantai Desa Tanjung Tiram menunjukkan bahwa suhu pada perairan tersebut merupakan suhu optimal bagi pertumbuhan lamun. 
Hasil pengukuran intensitas cahaya pada penelitian ini yaitu pada titik I 817 Cd, titik II 708 Cd dan titik III 778 Cd. Penetrasi cahaya matahari sangat penting untuk pertumbuhan lamun.Untuk mempertahankan populasinya tumbuhan lamun biasanya tumbuh pada perairan laut yang dangkal karena membutuhkan banyak cahaya matahari, namun lamun juga masih dapat tumbuh pada perairan yang dalam apabila kondisi perairan jernih.

Hasil pengukuran kedalaman perairan pada penelitian ini yaitu kedalaman $1 \mathrm{~m}, 2 \mathrm{~m}$ dan $3 \mathrm{~m}$. Lamun Enhalusacoroides

L. dan Halodulepinifolia banyak ditemukan pada kedalaman 1-2 m sedangkan pada kedalaman $3 \mathrm{~m}$ kedua jenis lamun tersebut sangat sedikit ditemukan. Hal tersebut sejalan dengan penelitian yang dilakukan Kikuchii dan Peres (1977) yang menyatakan bahwa tingkat kedalaman yang sangat tinggi akan mengurangi penyerapan cahaya oleh badan air, sehingga penyebaran padang lamun dipengaruhi oleh kedalaman perairan.

Hasil pengukuran salinitas pada penelitian ini yaitu pada titik I 31\%o, titik II 30\% dan titik III 30\%o.Lamun memiliki kemampuan toleransi yang berbeda terhadap salinitas, namun sebagian besar memiliki kisaran yang lebar yaitu $10-40 \%$.Nilai salinitas yang optimum untuk lamun adalah 35\%o.

Hasil pengukuran kekeruhan pada penelitian ini yaitu titik I 1,0 NTU, titik II 0,7 NTU dan titik III 0,5 NTU. Berdasarkan ketetapanKEPMEN LH No 51 Tahun 2004 tentang baku mutu air laut nilai kekeruhan untuk biota laut yaitu $<5$ NTU sehingga menunjukkan nilai kekeruhan yang diperoleh pada lokasi penelitian masih menunjukkan kisaran optimal bagi lamun.

Tipe substrat pada penelitian ini yaitu pada titik I pasir berlumpur, titik II pasir dan titik III pasir pecahan karang. Perbedaan komposisi jenis substrat akan dapat menyebabkan perbedaan komposisi jenis lamun dan juga suatu saat akan mempengaruhi perbedaan kesuburan pertumbuhan lamun. Hal ini didasari oleh perbedaan komposisi ukuran butiran pasir akan menyebabkan perbedaan nutrisi bagi pertumbuhan lamun dan proses dekomposisi dan mineralisasi yang terjadi di dalam substrat (Kiswara, 1992).

Kandungan organik total (KOT) yang diperoleh pada penelitian ini yaitu pada titik | 0,65\%, titik || 0,51\% dan titik III 0,27\%. Data tersebut menjukkan bahwa kandungan bahan organik total (KOT) tertinggi terdapat pada titik I 
dengan tipe substrat pasir berlumpur dan terendah pada titik III dengan tipe susbstart pasir pecahan karang. Rendahnya kandungan bahan organik dapat disebabkan oleh jenis substrat yang agak kasar (putri, dkk., 2016).

\section{Biomassa Lamun Enhalus acoroides L. dan Halodule pinifolia}

Biomassa Lamun Enhalus acoroides

L. dan Halodule pinifoliadisajikan pada Gambar 3 dan 4.

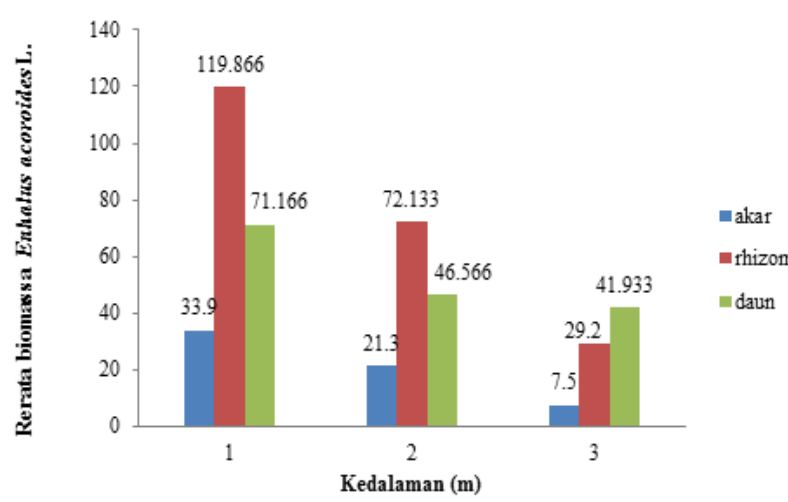

Gambar 2. Rerata Biomassa total lamun Enhalus acoroides L.

Berdasarkan data biomassa lamun jenis Enhalus acoroides L. yang diperoleh, kandungan biomassa tertinggi pada kedalaman $1 \mathrm{~m}$, bagian akar $41,76 \mathrm{~g} / \mathrm{m}^{2}$, bagian rhizoma $143,1 \mathrm{~g} / \mathrm{m}^{2}$ dan bagian daun 131,86 $\mathrm{g} / \mathrm{m}^{2}$, sedangkan kandungan biomassa terendah diperoleh pada kedalaman $3 \mathrm{~m}$, bagian akar 7,53 $\mathrm{g} / \mathrm{m}^{2}$, rhizoma $21,53 \mathrm{~g} / \mathrm{m}^{2}$ dan daun $9,2 \mathrm{~g} / \mathrm{m}^{2}$. Tingginya kandungan biomassa yang diperoleh pada kedalaman $1 \mathrm{~m}$ disebabkan oleh tipe substrat pada kedalaman $1 \mathrm{~m}$ yaitu pasir berlumpur yang merupakan tipe substrat yang baik untuk pertumbuhan Enhalus acoroides L. selain itu, kerapatan pada kedalaman $1 \mathrm{~m}$ juga relatif tinggi yaitu 21\%-33\%. Rendahnya kandungan biomassa jenis lamun Enhalus acoroides L. pada kedalaman $3 \mathrm{~m}$ dikarenakan tipe substrat pada kedalaman $3 \mathrm{~m}$ cenderung bepasir dengan campuran pecahan karang.

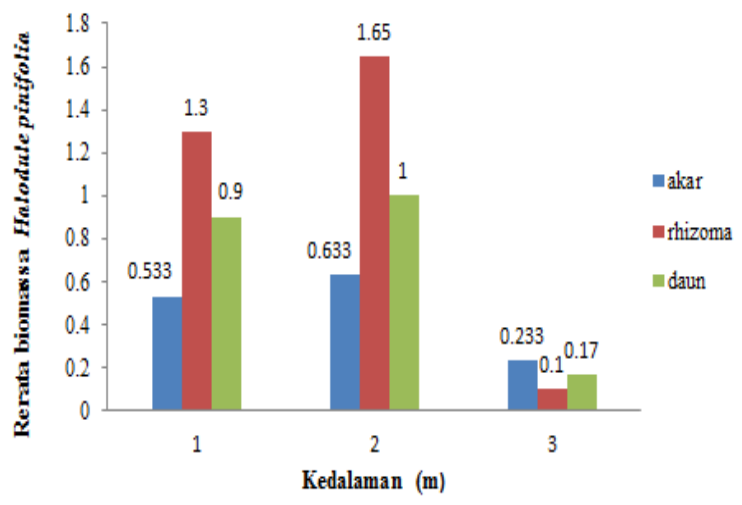

Gambar 3. Rerata biomassa Halodule pinifolia

Berdasarkan data biomassa lamun jenis Halodule pinifolia yang diperoleh, kandungan biomassa tertinggi yaitu pada kedalaman $2 \mathrm{~m}$, bagian akar $1,06 \mathrm{~g} / \mathrm{m}^{2}$, bagian rhizoma $0,93 \mathrm{~g} / \mathrm{m}^{2}$ dan bagian daun $0,96 \mathrm{~g} / \mathrm{m}^{2}$, sedangkan kandungan biomassa terendah diperoleh pada kedalaman 3 $\mathrm{m}$, bagian akar $0,13 \mathrm{~g} / \mathrm{m}^{2}$, rhizoma 0,06 $\mathrm{g} / \mathrm{m}^{2}$ dan daun $0,05 \mathrm{~g} / \mathrm{m}^{2}$. Tingginya kandungan biomassa yang diperoleh 
pada kedalaman 2 disebabkan oleh tipe substrat pada kedalaman $2 \mathrm{~m}$ cenderung berpasir yang merupakan tipe substrat yang di gemari oleh Halodule pinifoliauntuk tumbuh.Hal ini sesuai dengan Miranti (2014) yang menyatakan bahwa tipe substrat berpasir merupakan tipe substrat yang baik bagi pertumbuhan Halodule pinifolia.

\section{PENUTUP}

\section{Simpulan}

Simpulan pada penelitian ini adalah sebagai berikut :

1. Biomassa lamun jenis Enhalus acoroides L. yang terdapat pada kedalaman $1 \mathrm{~m}$ total biomassa $192,592 \mathrm{~g} / \mathrm{m}^{2}$, kedalaman $2 \mathrm{~m}$ total biomassa $140 \mathrm{~g} / \mathrm{m}^{2}$ dan kedalaman $3 \mathrm{~m}$ total biomassa $78,63 \mathrm{~g} / \mathrm{m}^{2}$. Biomassa lamun jenis Halodule pinifolia pada kedalaman $1 \mathrm{~m}$ total $2,733 \mathrm{~g} / \mathrm{m}^{2}$, kedalaman $2 \mathrm{~m}$ total biomassa $3,29 \mathrm{~g} / \mathrm{m}^{2} \quad$ dan kedalaman $3 \mathrm{~m}$ total biomassa 0,5 $\mathrm{g} / \mathrm{m}^{2}$.

2. Faktor lingkungan yang mempengaruhi kandungan biomassa lamun Enhalus acoroides L. dan Halodule pinifolia di perairan Pantai Desa Tanjung Tiram yaitu substrat, kandungan bahan organik (KOT), intensitas cahaya, suhu, salinitas dan kekeruhan.

\section{Saran}

Saran pada penelitian ini yaitu perlu dilakukan penelitian lebih lanjut mengenai kandungan stok karbon dan nutrien pada Enhalus acoroides L. dan Halodule pinifolia di Perairan Pantai Desa Tanjung Tiram, Provinsi Sulawesi Tenggara.

\section{DAFTAR PUSTAKA}

Dahuri, R., 2003, Keanekaragaman Hayati Laut Aset Pembangunan Berkelanjutan, Gramedia Pustaka Utama, Jakarta.

Hartog, D., 1970, Sructure Function and Classification in Seagrass Comunities, Seagrass Ecosystem : a Scientific Perspective, Marine Science, Marcel Dekker Inc, New York and Bassel.

Hendra, 2011, Pertumbuhan dan Produksi Biomassa Daun Lamun Halophila ovalis, Syringodium isoetifolium dan Halodule uninervis pada Ekositem Padang Lamun di Perairan Pulau Barrang Lompo, Skripsi, Universitas Hasanuddin, Makassar.

Keputusan Menteri Negara Lingkungan Hidup Nomor 51 Tahun 2004 Tentang Baku Mutu Air Laut, Departemen Lingkungan Hidup, Jakarta.

Kikuchi, T., and J. M. Peres, 1977, Cosumer Ecology of Seagrass Beds. In $\mathrm{mc}$ and $\mathrm{C}$. Helferich (eds). Saegrass Ecosystem, A scientific Perspective, Mar. Sci, 
Vol 4 Marcel Dekker Inc, New York: $357 \mathrm{pp}$.

Kiswara, W., 1992, Vegetasi Lamun (Seagrass) di Rataan Terumbu Pulau Pari, Pulau-Pulau Seribu, Jakarta, Oseonologi di Indonesia, 25 : 31-49

Marianti, Zulfikar, A., dan Zen, L.W., 2014, Klasifikasi Komunitas dan Afinitas Spesies Lamun Dikawasan Konservasi Laut Daerah Desa Berakit Kabupaten Bintan, FIKIP, UMRAH, Riau.

Putri, M.S.P, Suryanti, dan Widyorini, N., 2016, The Relation of Sediment Texture to Organic Matter and Macrozoobenthos Abundance in the Estuarine of Banjir Kanal Timur River. Saintek Perikanan,12(1) : 7580

Rahman, A.A., Nur, A.I., dan Ramli, M., 2016, Studi Laju Pertumbuhan Lamun (Enhalus acoroides.) di Perairan Pantai Desa Tanjung Tiram Kabupaten Konawe Selatan, Jurnal Sapa Laut Pebruari, 1(1) : 10-16
Ridio, A., 2004, Studi Potensi Lamun (Seagrass) di Perairan Jepara Sebagai Sumber Makanan Kesehatan : Analisis Asam Lemak, Universitas Diponegoro, Semarang.

Suherlan, Oetama, D., dan Arami, H., 2015, Keragaman Jenis Lamun di Perairan Waha Kecamatan Tomia Kabupaten Wakatobi, Jurnal Manajemen Sumber Daya Perairan, 1(3) : 311-321

Supriatna, A., 2017, Karakteristik Morfologi Alat Perkembangbiakan dan Pola Penyebaran Lamun (Seagrass)di Pantai Desa Tanjung Tiram Konawe Selatan Sulawesi Tenggara, Skripsi, Universitas Halu Oleo, Kendari.

Wakano, D., 2013, Seagrass Enhalus acoroides. Fruit Utilization as Alternative Food Sources Lomin Village Community East of Seram, Prosiding FMIPA, Universitas Pattimura. 